\title{
Use and Handling Practice of Pesticides in Vegetables: A Case Study on Some Selected Districts of Nepal
}

\section{PRAMOD KOIRALA ${ }^{1 *}$, ANANDA SHOVA TAMRAKAR ${ }^{1}$ BISHNU PRASAD BHATTARAI ${ }^{1}$, BIRENDRA KUMAR YADAV ${ }^{2}$ SAHADEV HUMAGAIN ${ }^{2}$ and YUBAK DHOJ G. C.}

\author{
${ }^{1}$ Central Department of Zoology, Tribhuvan University, Nepal \\ ${ }^{2}$ Himalayan College of Agricultural Sciences, Bhatakapur, Nepal \\ ${ }^{3}$ B. P. Koirala Institute of Health Sciences, Dharan, Nepal \\ ${ }^{4}$ Plant Protection Directorate, Lalitpur, Nepal
}

\begin{abstract}
A study was carried out to explore the present status of pesticides use and its handling practices on commercially grown vegetable pockets area of five districts namely; Tanahu, Chitwan, Kavre, Dhading and Bhaktapur of Nepal. Farmers were found to be using 24 types of pesticides in vegetables. The majority of used pesticides were moderately hazardous group of WHO classification. The analyses results revealed that the pesticides residues in vegetables were not detected below the level of $0.007 \mathrm{mg} / \mathrm{kg}$ by GLC and below the level of $0.05 \mathrm{mg} / \mathrm{kg}$ by Test-kit method. However, the handling practice of pesticides among farmers was not found as per the recommended procedure. Additionally, farmers were not aware of using personal protective equipments as well as taking adequate precautions during mixing, spraying and disposal of empty containers. Thus, awareness training to farmers on the use and handling of pesticides was assessed for pest management.
\end{abstract}

Keywords: Pesticides, Vegetables, Analysis, Use and handling practice, Health hazards

\section{Introduction}

Pesticides have contributed to dramatic increase in crop yields and in the quantity and variety of diet. Pesticides owing to their pest-destroying properties are required in global food production but they remain inevitably present as residues in food from both vegetal and animal origin. Therefore, occurrence of pesticide residue in food is an immense anxiety of everyone. (Koirala, 2009)

Pesticides despite on their known toxicity are widely used in developing countries. Their spectacular endeavor in preventing, crop preventing and controlling vectors of diseases have led to their reception and expanded use throughout the world. However, the controlling chemicals for killing pests have elevated alarm that they are agents of human diseases and environmental contamination. It has been pragmatic that their long period, low quantity contact is increasingly connection to human health effects such as immune-suppression, hormone disruption, diminished acumen, reproductive malfunction and cancer. Pesticide residues in food are comprehensive problems. (WHO-UNEP, 2006)

Pesticide pollution in the environment results disturbance of agro-environment system, residues in food and loss of biodiversity, develops pest resistance, secondary pest outbreak and economic loss to the users. (Koirala, 2008)

\footnotetext{
*Corresponding author, E-mail: pramodkoirala2002@yahoo.com ${ }^{1}$ Present address: Department of Food Technology and Quality Control, Babar Mahal, Nepal
}

Until the 1950s, the people of Nepal remained unaware of modern chemical pesticides and were dependent upon traditional organic techniques for killing pests. Chemical pesticides were first introduced to Nepal in 1952, when Paris green, Gammaxene, and Nicotine sulphates were imported from USA for malaria control. DDT was first imported in 1956. This was soon followed by a variety of other Organochlorines (in 1950s), Organophosphates (in1960s), Carbamates (in 1970s), and synthetic Pyrethroids (in 1980s) (Koirala, 2010). In Nepal, pesticide issue is one of the concerns of food control agency, consumers associations and general public as well. Consumers in urban areas are more conscious towards their health and willing to know the status of pesticide use in their food. Similarly, media and some consumer associations are putting pressure to the Government to solve problems of these areas. It is also blamed that vegetable growers at commercial vegetables pockets of nearby urban areas are using more pesticides in their crops, thereby affecting the health of consumers in urban areas. Therefore, this study was carried out to know the existing status of pesticide use in the commercial vegetable pockets in five districts of Nepal.

In this context, our objective of this work was to contribute the technical inputs for the preparation of national database on pesticide use in Nepal as well as to assess the types of pesticides using in farm levels, their handling practices and residue level in vegetables grown area.

\section{Methodology}

Sampling design and survey: This study covered five districts of Nepal namely; Tanahu, Chitwan, Kavre, Dhading and Bhaktapur, which are leading producers for vegetables as 
compared to others. These districts supply the vegetables to Kathmandu valley and other major cities of Nepal.

Altogether 50 respondent farmers were selected in this study representing 10 from each district. An organized questionnaire was prepared to gather the information related to use of pesticides in vegetables, pesticide handling practice, experience of health hazards, use of personal protective equipment, training needs during this study.

Pesticides analysis: Vegetables from surveyed areas were collected for pesticide residue analysis. Vegetable samples were analyzed by using two different methods in laboratory. The total of 25 samples was analyzed using the Test-kit developed by Department of Medical Science, Ministry of Public Health, Thailand and the other method was by using Gas Liquid Chromatography (GLC). Among them, five samples were analyzed for pesticide residue analysis to verify the laboratory result. The pesticides were analyzed semiquantitatively by following the manual of Kit producer.

\section{Results and Discussion}

Socio-demographic information: There were five districts covered in this study namely; Tanahu, Chitwan, Kavre, Dhading and Bhaktapur, where fifty farmers growing vegetables were included in this study. The demographic information showed that majority of farmers (70\%) engaged in agriculture for more than ten years (Figure). Half of the farmers were using pesticides for more than ten years. Nearly half $(46 \%)$ spent more than $4 \mathrm{hrs}$ daily in their fields. Pesticides were normally sprayed by males (more than three in four, $\sim 78 \%$ ) members. Children were not found to be allowed for spraying of such pesticides.

Mean size for land holding respondent farmers were found to be varied in different districts. The highest was found in Chitwan (i.e. 3 Acre) and the lowest was in Bhaktapur (i.e.1 Acre). The survey showed that $52 \%$ of farmers were spending money for pesticides regularly of the worth more than Nrs. 3000.00 per year.

Use of pesticide in vegetables: During the survey, 24 types of pesticides have been found in use by the farmers (Table 1).

Types of pesticides used in fields: A registered pesticide has two names. The common name is given it by international organizations or national standards. The proprietary name is the name given it by the manufacturer, also known as the trade name. Both names must appear on the label but the proprietary name is usually more prominent. Nevertheless, it is a common or approved name that is important, especially when poisoning occurs, as it gives clues to the chemical group to which the compound belongs (IPCS, 2005).

The group-wise classification of pesticides using in the field was observed. Organophosphates occupy the highest position according to its use followed by pyrethroids. Besides of these, Chlorpyrifos and Cypermethrin were the two common groups of pesticides applied in the field. Among the fungicides, Carbendazim under different trade name was used in the field (Figure 1). The survey research showed that the frequency of pesticide use depends on pest attack to the

Table 1: Pesticide applied in the field during the survey

\begin{tabular}{lccc}
\hline \multicolumn{1}{c}{ Pesticides } & Chemical type* & Main use & WHO Class \\
\hline Decis & PY & Insecticide & II \\
Rogor & OP & Insecticide & II \\
Thiodan & OC & Insecticide & II \\
Devicyper & PY & Insecticide & II \\
Record & PY & Insecticide & II \\
Super D & OP & Insecticide & II \\
Nuvan & OP & Insecticide & IB \\
Anumite & PY & Insecticide & II \\
Anumida & O & Insecticide & II \\
Jackpot 10 & PY & Insecticide & II \\
Deviban & OP & Insecticide & II \\
Nurami & OP & Insecticide & II \\
Devimono & OP & Insecticide & IB \\
Metacid & OP & Insecticide & IA \\
Gajani & O & Insecticide & II \\
Dhanuka & OP & Insecticide & II \\
Devikol & OP & Insecticide & IB \\
Ammo & PY & Insecticide & II \\
Superlethal & OP & Insecticide & II \\
Dolphin & OP & Insecticide & II \\
Silcord & PY & Insecticide & II \\
Diethan M 45 & F & Fungicide & NH \\
Krilaxyl & F & Fungicide & NH \\
KI BESTIN & F & Fungicide & NH \\
*OC= Organochlorine, OP $=$ Organophosphate, PY= Pyrethroid, F= Fungicides, O= Others, \\
IA= extremely hazardous, IB= highly hazardous, II= moderately hazardous III= slightly hazardous, H= \\
none hazardous & & &
\end{tabular}


vegetables. Nearly half of farmers $(\sim 44 \%)$ apply pesticides 3 4 times in one crop cycle. The common and trade name of pesticides are given in Table 2.

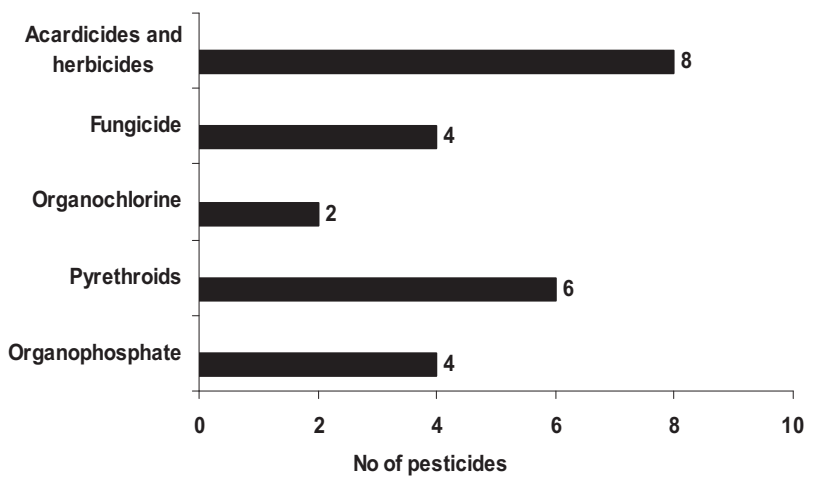

Figure 1. Pesticide used in the field, $n=24$

Types of pesticides used according to hazard level of WHO: The pesticides hazards have been classification by WHO (Figure 2). Different group represents hazard level given below in table. According to this classification, the pesticides used in the field were found as given in Figure 2. The majority belongs to moderately hazardous class II.

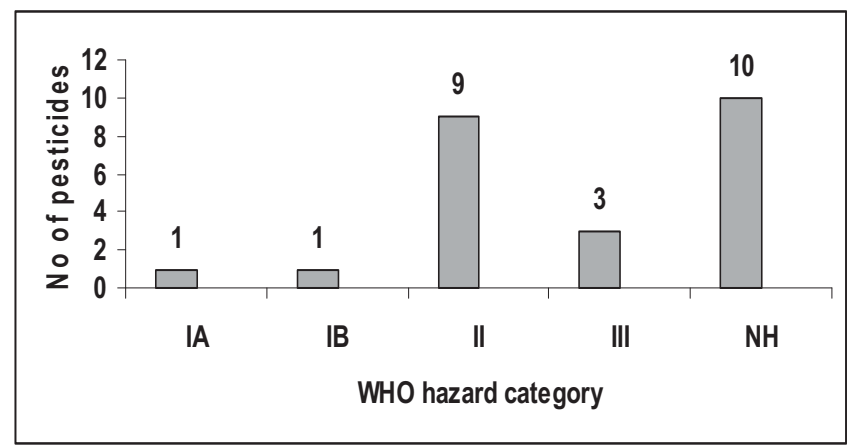

Figure 2. Pesticides used according to the hazard level of WHO

Note: $\mathrm{IA}=$ extremely hazardous, $\mathrm{IB}=$ highly hazardous, $\mathrm{II}=$ moderately hazardous $\mathrm{III}=$ slightly hazardous, $\mathrm{H}=$ none hazardous
Laboratory analysis of pesticides: Pesticides can be used in agricultural produces in various ways, such as to control the growth of weeds as well as to prevent crop damage by pests. In some instances, pesticides residues can remain in or on food after harvesting, storage and even processing. The levels of residues present are usually low and are expressed in $\mathrm{mg} / \mathrm{kg}$ of crop, food or commodity ( $\mathrm{mg} / \mathrm{kg}$ or ppm). Maximum residue limit are established to ensure that the total consumption of residues from all food uses will not exceed the acceptable daily intake (ADI). Unlikely high levels of residues in food can occur, when the amount of pesticides applied exceeded the recommended doses or the interval between spraying and harvesting was not monitored.

Now-a-days, the several methods for the pesticide residues analysis are available, but the investment cost is very high. They need a long analysis time with the advance instruments, such as TLC, GC, LCMS and GC-MS. Therefore, the simple kit for screening the pesticides (Organophosphates and/or Carbamates) with the fast reliable result has been developed by Department of Medical Sciences, Ministry of Public Health, and Thailand. The total of 25 samples was analyzed using the Test-kit; however, the result showed that no pesticides were detected in the test samples at the detection level of $0.05 \mathrm{mg} /$ $\mathrm{kg}$.

Five samples were analyzed for pesticide residue analysis to verify the laboratory result. GLC of Thermo, UK was used to analyze the pesticides at the detection level of $0.007 \mathrm{mg} / \mathrm{kg}$. The pesticide analysis results showed that it was not detected at the level of $0.007 \mathrm{mg} / \mathrm{kg}$.

Pesticides handling practice: The first step in the use of any pesticide is to read the label. One should never use a pesticide from an unlabelled container. A pesticide should not be poured into an unlabelled container unless it is to be diluted and used immediately. Mixing pesticides involves dilution of concentrated formulations to prepare a solution for application. It doesn't mean mixing two separate pesticide formulations, which is an unacceptable practice unless it is clearly stated on the label that the two formulations are

Table 2. Common and trade name of pesticides applied in the fields

\begin{tabular}{lll}
\hline Pesticide group & Common name & \multicolumn{1}{c}{ Trade name } \\
\hline Organochlorine & Endosulfan & Thiodan \\
Organophosphate & Dimethoate & Rogor \\
& Chlorpyrifos & $\begin{array}{l}\text { Super D, Deviban, Nurami, Dhanuka, Superlethal } \\
\text { (Chlorpyrifos+ Cypermethrin ), Dolphin }\end{array}$ \\
& & (Chlorpyrifos+ Cypermethrin ) \\
& Dichlorvos & Nuvan, Devikol \\
& Monochrotophos & Devimono \\
Pyrethroids & Cypermethrin & Devicyper, Reord, Anumite, Jackpot 10, Superkiller, Silcord \\
Fungicides & Carbandazim & Carbandazim, Dimethan M 45, Krilaxyl \\
Others & Imidachlorpid & Anumida, Gajani, Confident \\
\hline
\end{tabular}


compatible. The hazard to mixer is greater than that to the applicators. Therefore, the mixer needs more protection of the body feet, hands, eye and other body parts. During the field survey, most of the farmers were not taking care of protection of their body. They were using without care and is a serious problem among the pesticide applicators.

Since all pesticides are toxic in nature, their handling and disposal should be according to the recommended practice. Farmers during the application were found taking adequate care of pesticides because nearly all used to determine the wind before the application of pesticides. During the application of pesticides, there should be the display of signboard to inform others. But none of the farmers were found following it.

The empty containers of pesticides should be marked and stored in a safe place before disposal. Container rinsing solution need not become pesticide waste as it can be added in to the pesticide tank during mixing. The survey result showed, that more than one-third (38\%) of the farmers thrown away pesticide containers anywhere, without taking of adequate care. However, a significant number of farmers have started the practice of selling it to other buyers. Others either burnt $(15 \%)$ or buried in the ground $(7 \%)$.

Pesticides and health hazards to the farmers: Pesticides contamination in food or drink may cause acute and chronic effects on human health. Exposure to a pesticide can occur over a short period or can be continuous or repeated. Passive non-occupational exposure could result from contamination of food, water, soil or air. In the surveyed areas very few farmers (only 10\%) were found suffered from pesticide hazard. This might be due to the long term effect of pesticides. Around $10 \%$ farmers were encountered the problem of pesticides in their health. Eye/skin irritation and headache was the major symptoms associate with it. It is important to avoid absorption of pesticides through skin, lungs, eyes and mouth.

The objective of personal protection equipments (PPE) is to keep the exposure of such hazards to field level workers. The type of protective clothing will depend on the hazards of the formulation. All workers should know the hazard of the work that they are required to carry out. Pesticides should be applied only with good, well-maintained equipment to reduce leaks and spillages.

In the surveyed area, only $70 \%$ farmers were using PPE. Others did not use it. The majority of the farmers were not wear gloves and masks (40\% and 44\% respectively). Similarly, $30 \%$ were nor using even shoes during the application of pesticides. None of the farmer during the spray was found to be used eye glass.

After spraying the pesticides, personal cleanliness is essential to remove pesticide contamination from the body. The result showed that more than a half $(\sim 52 \%)$ was found taking a bath after spray. This may cause the possibility of several hazardous effects on human health on long run basis.

Training need and alternative techniques of pesticides: Several pests or vectors can be managed by various methods. The control method so chosen should be adapted in the local conditions and pesticides should be used in proper standard way. Examples of non-pesticide control options that can be a parts of integrated pest and vector management include; in agricultural pest control (Cultural practices, including crop rotation, crop diversity, timing of planting); sanitation and creation of buffer zones; biological control agents; environmental management including community surveillance actions. More than two-third surveyed farmers received the training on pesticides. All of them received training conducted by Ministry of Agriculture and Cooperatives.

Opinions on pesticides use: Around $88 \%$ of farmers expressed their opinion to reduce the chemical pesticides in future, whereas very few had their opinion to either keep it as same or to increase in the future (Figure 3).

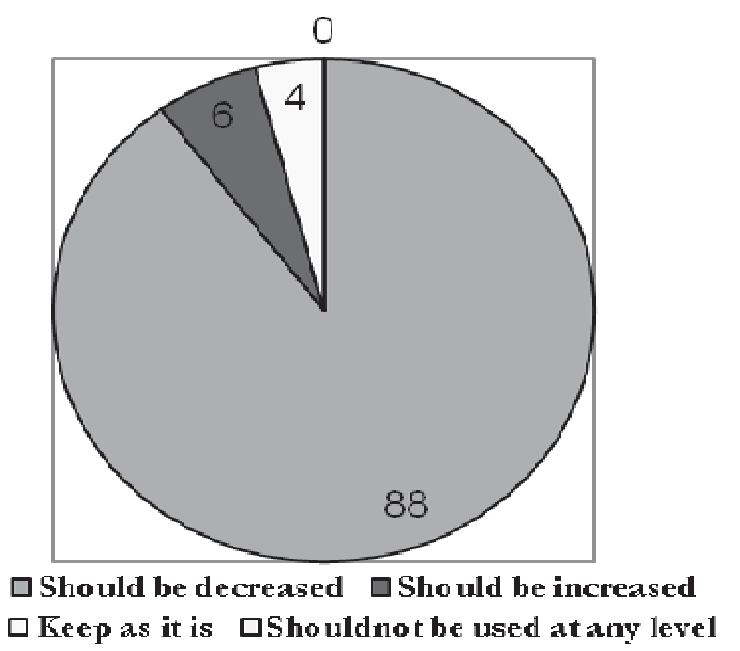

Figure 3. Farmers' opinion on pesticide use

Integrated pest management (IPM) means the careful consideration of all available pest control techniques and subsequent integration of appropriate measures that discourage the development of pest populations, keep pesticide use and other intervention on the levels that are economically justified and reduce or minimize risks to human health and the environment. In the surveyed area, more than 2 out of $3(68 \%)$ heard about IPM. But in practice, there was none of the farmers were adopting IPM in their fields.

When the farmers were asked the types of training they are in need, majority replied that they need the training in the area of use and application of safe pesticides such as bio-pesticides and also technique to decrease chemical pesticide in vegetables. The training demanded by farmers is given in Table 3 . 
Table 3. Training needs assessment to the farmers

\begin{tabular}{lcc}
\hline Training need assessment & No. of Farmer & \% of Farmer \\
\hline Technique to decrease pesticide use in vegetables (Such as IPM) & 10 & 20 \\
Training on safe handling of chemical pesticides & 5 & 10 \\
Training on Equipment handling (Equipment safety) and use of PPE & 10 & 20 \\
Training on use of safer pesticides (Botanicals and other bio-pesticides) & 11 & 22 \\
General awareness on health hazards of pesticides & 10 & 20 \\
Do not know & 4 & 8 \\
Total & 50 & 100 \\
\hline
\end{tabular}

\section{Conclusion and Recommendation}

During the field visit, it was observed that there were 24 types of pesticide are using by farmers. The average application frequency of pesticides was 2 to 2 times in one crop cycle for vegetables. Majority of pesticides belong to Organophosphates group. According to WHO classification of hazard, pesticide often used in the field fall under the category of moderately hazardous group (Group II). Chlorpyrifos and Cypermethrin were the two major pesticides used under the different proprietary names. Use of extremely hazardous pesticide Endosulfan was also found in the field. However, further research on pesticides residues using more sophisticated equipments is recommended in future.

The analysis result for 25 samples of vegetables revealed that pesticide residues present in vegetables were either the below detection level by the test kit or free from pesticide residues.

Additionally, farmers were not taking adequate safety measures during mixing, spraying and disposal of empty pesticide containers. There is no practice of "triple rinsing". Many farmers were found less informed on the importance of personal protective equipment. However, they were demanding trainings on alternative technology that rely on less use of such chemicals for pest management. Therefore, it is apparently seemed that the training on pesticides handling, disposal and dissemination of alternative technology through training and field demonstration is essential to minimize the chemical hazards in future.

\section{Acknowledgements}

The authors would like to express their gratitude to FAO/IPM program of Government of Nepal for providing financial support for this study.

\section{References}

IPCS (2005). The WHO Recommended Classification of Pesticides by Hazard and Guidelines to Classification 2004, WHO, Geneva.

Koirala P., Dhakal S. Tamrakar A. S. (2009). Pesticides and Food Safety Issues in Nepal. The J. of Agri. and Environment, Ministry of Agriculture and Cooperatives, Nepal, 9:25-28.

Koirala P. and Tamrakar A. S. (2010). Study on pesticide residue monitoring program and quarantine system of some selected Asian countries. J. of Food Sci. and Tech. Nepal, 5:23-26.

Koirala P., Dahal N. R. Dhakal S., Dhungel Y. and Lama J. P. (2008). Pests Ubiquitous and Use of Pesticides in Vegetables in Eastern Development Region of Nepal. Food Res. Bulletin, Department of Food Technology and Quality Control Kathmandu, Nepal.

WHO-UNEP (2006). Sound Management of Pesticides and Diagnosis and Treatment of Pesticide Poisoning: A Resource Tool, WHO, Geneva. 